\title{
Encapsulation of implantable integrated MEMS pressure sensors using polyimide epoxy composite and atomic layer deposition
}

\author{
P. Gembaczka ${ }^{1}$, M. Görtz ${ }^{1}$, Y. Celik ${ }^{1}$, A. Jupe ${ }^{1}$, M. Stühlmeyer ${ }^{1}$, A. Goehlich ${ }^{1}$, H. Vogt $^{1}$, W. Mokwa ${ }^{2}$, \\ and M. Kraft ${ }^{1}$ \\ ${ }^{1}$ Fraunhofer Institute for Microelectronic Circuits and Systems, Duisburg, Germany \\ ${ }^{2}$ Institute of Materials in Electrical Engineering, RWTH Aachen University, Aachen, Germany \\ Correspondence to: P. Gembaczka (pierre.gembaczka@ims.fraunhofer.de)
}

Received: 21 July 2014 - Revised: 21 November 2014 - Accepted: 25 November 2014 - Published: 19 December 2014

\begin{abstract}
Implantable MEMS sensors are an enabling technology for diagnostic analysis and therapy in medicine. The encapsulation of such miniaturized implants remains a largely unsolved problem. Medically approved encapsulation materials include titanium or ceramics; however, these result in bulky and thick-walled encapsulations which are not suitable for MEMS sensors. In particular, for MEMS pressure sensors the chip surface comprising the pressure membranes must be free of rigid encapsulation material and in direct contact with tissue or body fluids. This work describes a new kind of encapsulation approach for a capacitive pressure sensor module consisting of two integrated circuits. The micromechanical membrane of the pressure sensor may be covered only by very thin layers, to ensure high pressure sensitivity. A suitable passivation method for the high topography of the pressure sensor is atomic layer deposition (ALD) of aluminium oxide $\left(\mathrm{Al}_{2} \mathrm{O}_{3}\right)$ and tantalum pentoxide $\left(\mathrm{Ta}_{2} \mathrm{O}_{5}\right)$. It provides a hermetic passivation with a high conformity. Prior to ALD coating, a high-temperature resistant polyimide-epoxy composite was evaluated as a die attach material and sealing compound for bond wires and the chip surface. This can sustain the ALD deposition temperature of $275^{\circ} \mathrm{C}$ for several hours without any measurable decomposition. Tests indicated that the ALD can be deposited on top of the polyimide-epoxy composite covering the entire sensor module. The encapsulated pressure sensor module was calibrated and tested in an environmental chamber at accelerated aging conditions. An accelerated life test at $60^{\circ} \mathrm{C}$ indicated a maximum drift of $5 \%$ full scale after $1482 \mathrm{~h}$. From accelerated life time testing at $120^{\circ} \mathrm{C}$ a maximum stable life time of 3.3 years could be extrapolated.
\end{abstract}

\section{Introduction}

The development of small MEMS (micro-electro-mechanical systems) sensors with functional surfaces enables the ability to perform diagnostic and therapeutic tasks inside the human body in the form of a long-term implant. Application examples include continuous pressure monitoring (Mokwa, 2007; Gembaczka et al., 2013), nerve and muscle stimulation (Eick et al., 2009) and drug delivery systems (Hang Tng et al., 2012). Usually medically approved micro-electronic implants such as pacemakers (Park and Lakes, 2007), cochlear implants (Loeb, 1990) or brain stimulators (Rezai et al., 2002) are encapsulated by non-flexible materials such as ti- tanium or ceramics with considerable sidewall thickness in the range of $100 \mu \mathrm{m}$ to $1 \mathrm{~mm}$. Such hermetic encapsulations do not allow individual regions of the sensor to be in direct contact with the tissue or body fluids, as required for pressure sensing. Furthermore, in applications like retinal implants, where bendability of the implant is needed, the limits of miniaturization of thick-walled encapsulation materials are quickly reached. To take full advantage of MEMS sensors a paradigm shift from voluminous and solid encapsulations towards miniaturized and flexible encapsulations is required.

The measurement of pressure in different areas of the human body, such as blood pressure (in large arteries or veins), intraocular pressure or intracranial pressure is important for 
medical diagnostics and therapy (Mokwa, 2007). The continuous monitoring of the corresponding pressure values with a permanent implant can be beneficial for the treatment of medical conditions such as intracranial and arterial hypertension, heart insufficiency and glaucoma.

The development of a miniaturized encapsulation technology for MEMS pressure sensors is particularly challenging as the pressure outside of the housing must be transferred to a pressure-sensitive membrane. A number of approaches for the encapsulation of implantable pressure sensors have been suggested previously (Mokwa, 2007). Silicone is often used as encapsulation material because it is soft and can transmit the pressure well (Cleven et al., 2012; Bradford et al., 2010; Stangel et al., 2001). However, silicones absorb water and the material properties change over time leading to a drift of the pressure value measured by the sensor. Preconditioning of the material and offset compensation of the sensor can alleviate the problem (Gräfe et al., 2009). Nevertheless, water diffusion remains problematic especially with electrical components inside the human body. Materials like Parylene$\mathrm{C}$ were applied to further reduce the water uptake (Schlierf et al., 2005) or the membrane of the pressure sensor was directly made of parylene (Ha et al., 2012; Chen et al., 2008). However, a hermetically sealed encapsulation is not achievable based on polymer alone, therefore novel solutions must be developed.

The pressure sensor employed in this work is fabricated in CMOS technology allowing the integration of a capacitive pressure sensor with the read-out electronics on one chip. For some applications a second chip is required for signal processing. A hard and thick passivation would change the characteristics of the sensitive membranes of the pressure sensor chip so strongly that no sufficient pressure transmission would be possible. In previous preliminary work, an encapsulation concept for the pressure sensor surface based on atomic layer deposition (ALD) was successfully tested (Betz, 2011). A passivation layer consisting of $50 \mathrm{~nm} \mathrm{Al}_{2} \mathrm{O}_{3}$ and $50 \mathrm{~nm} \mathrm{Ta}_{2} \mathrm{O}_{5}$ was deposited by ALD on the pressure sensor chip only. Figure 1 shows the pressure membranes and part of the readout electronics after an accelerated life time test in phosphate-buffered saline (PBS) at $150^{\circ} \mathrm{C}$ for $1 \mathrm{~h}$. Although the test results were encouraging, first indications of corrosion were observed at the aluminium bond pads and the saw edges of the chip. This was attributed to the inhomogeneity of the sawing process (Betz, 2011).

In a novel encapsulation concept, therefore, the electrical contacts of the chip, the bond wires and the dicing-edges have to be protected before ALD passivation. ALD deposition is performed at a temperature of $275^{\circ} \mathrm{C}$ for several hours. All components of the system, including the protective material, have to be resistant to this temperature. In this study we used the high-temperature resistant polyimideepoxy composite Polytec EP P-690 (Polytec PT GmbH, 2011 ) as a protective casting material, which serves as a dieattach material, sealing compound for the bond wires and the

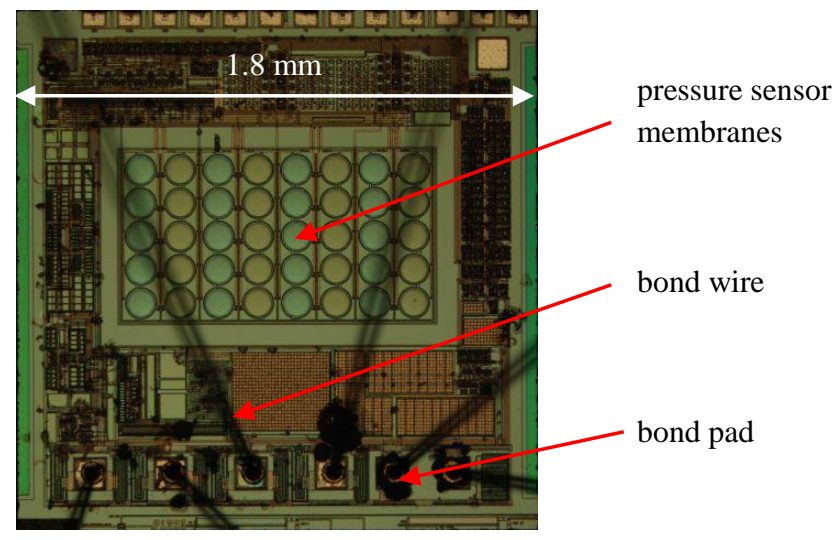

Figure 1. Photo of the pressure sensor chip after $1 \mathrm{~h}$ in PBS at $150{ }^{\circ} \mathrm{C}$ (Betz, 2011).

chip surface. However, there is no commercially available material optimized for such an application.

Particularly problematic is that polyimide-epoxy significantly shrinks during the curing phase. A process had to be developed to circumvent the shrinkage. For the first time, this work reports on a biocompatible encapsulation method combining ALD and polymers.

The paper is organized as follows: in Sect. 2 an assembly of a two-chip pressure sensor module (pressure sensor chip including read-out electronics and signal processing chip) is introduced to facilitate the development of novel encapsulation and assembly technique. Section 3 describes the hightemperature resistant polyimide-epoxy composite and its deployment. In Sect. 4, the ALD layer is discussed and test results regarding the hermetic seal of the sensor are presented. Section 5 presents pressure sensor module calibration and measurement results at various temperatures, and Sect. 6 accelerated life time testing results. Finally, in Sect. 7 some conclusions are drawn.

\section{Components and materials of the pressure sensor module}

The pressure sensor module mainly consists of two application-specific integrated circuits (ASICs). The first is the capacitive pressure sensor chip (PS) including the read-out electronics, the second a signal post-processor chip (SPP). Both are mounted on a silicon chip carrier with bond pads and signal tracks. Additionally, some surface mount components (SMD) are required. The cross-section of the pressure sensor module is depicted in Fig. 2. In the first step, the chips were glued on the chip carrier using a polyimideepoxy composite and electrically connected to the carrier with bond wires. The bond wires and the entire module, except for the pressure sensor membranes, were covered with the same polyimide-epoxy composite (as described in 

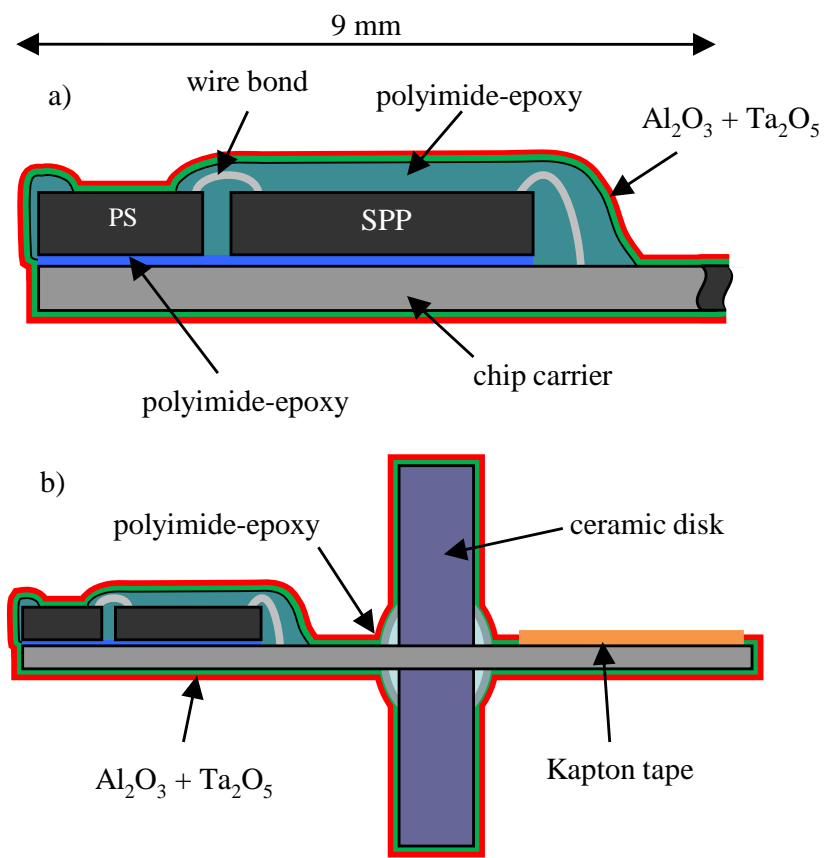

Figure 2. (a) Sketch of the pressure sensor module and encapsulation concept in cross-section. (b) Schematic representation of the entire sensor assembly with ceramic disc separator and taped pad structures.

Sect. 3) used for die attachment to minimize thermal expansion stress.

We choose here the approach to encapsulate the chips by polyimide-epoxy first, and then by an ALD layer to achieve a hermetically sealed passivation. Considering the opposite approach, application of a polymer potting layer on top of the ALD layer is not a viable solution, as the bond wires mechanically deform die to shrinkage of the polyimide-epoxy in the curing process, which, in turn, would lead to miniature fractures of the ALD layer. Another disadvantage is the water uptake of the polyimide-epoxy which leads to changes of the material properties of the polymer over time. The water uptake of polymer is very low but the pressure sensor is highly sensitive to any kind of mechanical stress and, in general, any change of the material properties leads to drift of the measured pressure value. Here, it was therefore chosen to apply first a layer of polyimide-epoxy followed by ALD deposition to create a water impermeable, hermetic encapsulation.

A ceramic disc with an opening for the chip carrier was placed next to the ASICs and fixed with the same polymer. The disc serves as a separation between the ASICs that are exposed to the medium on one side and the discrete circuit components on the other side; this is depicted in Fig. 2b. The overall assembly of the separation disc and the discrete components is not the subject of this paper and therefore shall not be described in further detail. The final step (described in more detail in Sect. 4) is the passivation of the entire as-

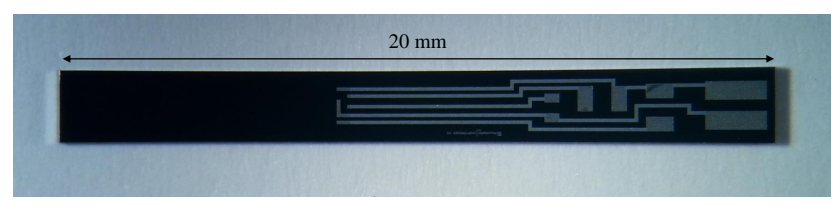

Figure 3. Photo of the silicon chip carrier.

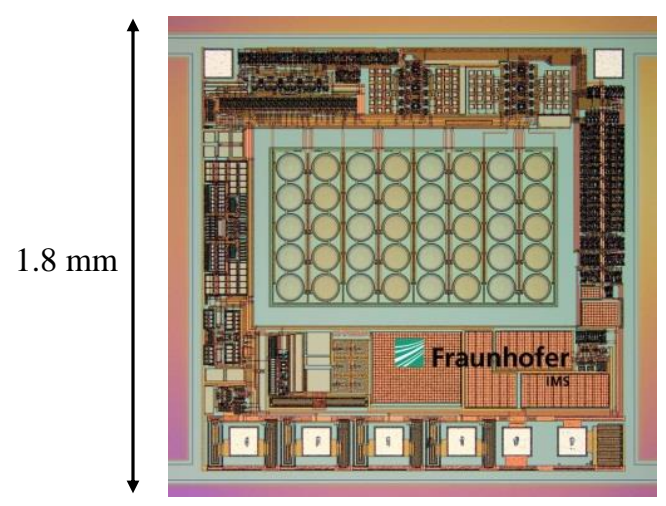

Figure 4. Photograph of the capacitive pressure sensor chip before encapsulation (Betz, 2011).

sembly in an ALD tool with aluminium oxide $\left(\mathrm{Al}_{2} \mathrm{O}_{3}\right)$ and tantalum pentoxide $\left(\mathrm{Ta}_{2} \mathrm{O}_{5}\right)$.

Only the hermetically sealed area located left of the ceramic disc is later exposed to the liquid medium.

\subsection{Silicon chip carrier}

The carrier for the entire sensor module is made of a silicon chip with aluminium tracks (for the discrete components), pads and space for the pressure sensor chip and the SPP, as shown in Fig. 3. The chip carriers are processed at wafer level and diced into separate chips.

Silicon as a carrier material was selected because it has the same thermal expansion coefficient as the ASICs. The thermal expansion of different materials is critical in this passivation method, as thermal stress can lead to fractures.

\subsection{Capacitive pressure sensor chip}

The pressure sensor chip has been fabricated in a CMOS technology allowing the integration of capacitive pressure sensor membranes with the readout electronics in a surface micromachining process. The chip size is $1.8 \times 1.8 \mathrm{~mm}^{2}$ and is shown in Fig. 4.

The bottom electrode of the pressure sensor is made of $n^{+}$doped silicon, whereas the upper electrode is made of a flexible polysilicon membrane, as shown in Fig. 5. By applying pressure to this assembly, the distance between the two electrodes is changed resulting in change of the capacity $C_{\text {sens. }}$. The pressure sensor has already been described in 


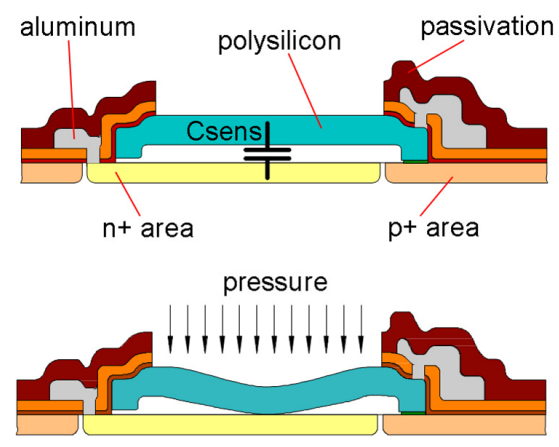

Figure 5. Section through a pressure sensor membrane (Trieu, 2011).

more detail in Dudaicevs et al. (1994), Müntjes et al. (2010), Trieu (2011) and Gembaczka et al. (2013).

In order to achieve a sufficiently large change of the capacitance, 20 identical pressure sensor membranes are combined into an array. The pressure sensor chip is not only sensitive to the applied pressure, but due to its micro-mechanical structure, also to mechanical stress induced, for example, by the different thermal expansion coefficients of the chip and the adhesive materials. Consequently, a soft silicone is typically used as adhesive to mechanically decouple the chip. However, due to the ALD deposition temperatures of $275^{\circ} \mathrm{C}$ any silicone will exhibit considerable thermal change. Furthermore, the difficult topography of the pressure sensor chip restricts the choice of a suitable passivation material. Figure 6 shows the cross-section of an area of the pressure sensor depicting this issue clearly.

\subsection{Signal-post-processing chip}

To get a functional pressure sensor module a second ASIC is required to digitize the analogue pressure sensor signals. The SPP chip shown in Fig. 7 was fabricated in a $0.35 \mu \mathrm{m}$ CMOS technology with a size of approximately $1.8 \times 5 \mathrm{~mm}^{2}$.

The width of the ASIC is identical to the width of the pressure sensor chip. The ASIC has a temperature sensor integrated based on a bipolar transistor with the necessary read-out circuits. The temperature measurement is used to compensate the temperature dependence of the pressure sensor. In addition to an analogue-to-digital converter the SPP includes a voltage regulator, a local oscillator and an EEPROM for permanent storage of calibration and identification data (Gembaczka et al., 2013). With a two-wire connection cable, the digitized sensor data is transmitted to a data reader. The connection is used both for data transmission and power supply.

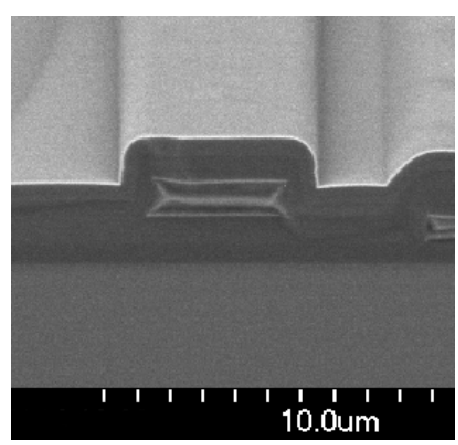

Figure 6. Cross-section SEM image of an area of the pressure sensor illustrating the difficult topography for encapsulation.

\section{Encapsulation with high-temperature polyimide-epoxy composite}

\subsection{Choice of material}

For the first encapsulation layer of the pressure sensor module a polymer had to be found satisfying all requirements. The same material should be used for the die-attach and the potting of the pressure sensor module including the bond wires. This has the advantage that thermal expansion coefficients are identical avoiding tension and thus cracks in the assembly.

Ideally, the material should satisfy the following requirements:

- long-term temperature stability up to $275^{\circ} \mathrm{c}$

- high glass transition temperature

- low thermal expansion

- thermally conductive

- electrically insulating

- good adhesive properties

- smooth surface without pores

- dispensable

- thixotropic

- CMOS compatible.

The desired properties, in particular the temperature stability, drastically reduce the list of candidates of possible polymers. With regard to the processability and adhesion, an epoxy is a good choice for potting. Epoxy resins with different modifiers are available to improve material properties, for example rubber additives for flexibility (Boyle et al., 2001). One disadvantage is the decomposition and deformation of polymers (Beyler and Hirschler, 2001; Cheng et al., 2009). Some electrically insulating high-temperature epoxy 


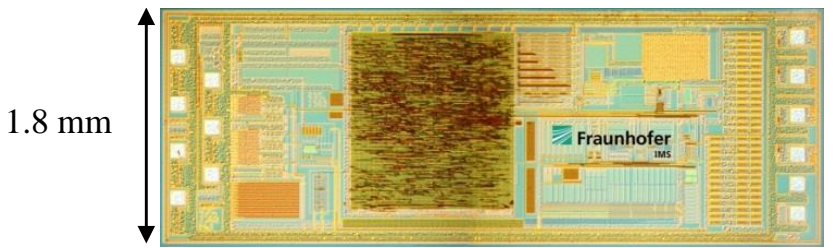

Figure 7. Photograph of the SPP-chip.

composites already exist that allow operating temperatures up to about $260^{\circ} \mathrm{C}$, for example the Duralco 4461 (Polytec PT $\mathrm{GmbH}, 2010$ ) has a maximal operating temperature of $260^{\circ} \mathrm{C}$ but the deformation temperature is about $210^{\circ} \mathrm{C}$ hence it is not suitable for the envisaged application. To obtain a homogeneous and defect-free ALD passivation layer the polymer must not deform during heating or cooling processes.

Alternatively, polyimides are materials satisfying nearly all requirements and are well established for applications in microsystem technology (Walewyns et al., 2013). However, processing of polyimide is challenging due to the evaporation of the solvent (for example N,N'-Dimethylformamid, N,NDimethylacetamid or N-Methylpyrrolidon) (Calderón, 2005) and water during the curing process (or imidization) leading to a significant shrinkage of the material which is especially problematic for the encapsulation of the bond wires. Another critical point is the adhesion of pure polyimide which is typically rather poor (Gaw and Kakimoto, 1999). The bonding of two objects is difficult because of the evaporation of the solvent creating pore-like structures during the curing process. The pores are also problematic for a hermetic ALD passivation layer; therefore pure polyimides are also not suitable for the pressure sensor module encapsulation. In particular synthesized polyimides with additives allow improving some material properties; examples include $U$-Varnish-S (UBE) or PI2611 (HD Microsystems) which exhibit lower water absorption than basic polyimides (Rubehn and Stieglitz, 2010) and were used for neural implants (Hassler et al., 2011).

In particular, polyimide-epoxy composite was identified as a suitable material; here a small amount of epoxy (typically $10-15 \%$ ) is added to the polyimide partially replacing the solvent (Gaw and Kakimoto, 1999). This increases adhesive strength, shape stability and reduces the formation of pores.

For the encapsulation of the pressure sensor module we used Polytec EP P-690 (Polytec PT GmbH, 2011). The shrinkage during curing was still significant as well as the formation of pore-like structures, but less than in pure polyimides. To address the remaining problems, we developed a curing process to minimize these issues

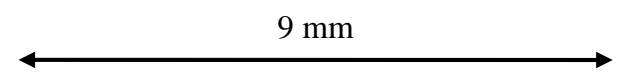

a)

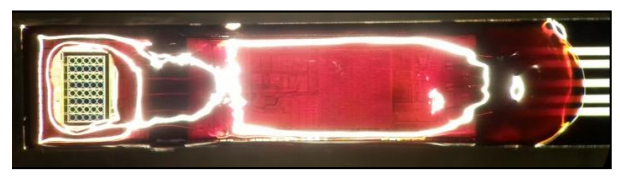

b)

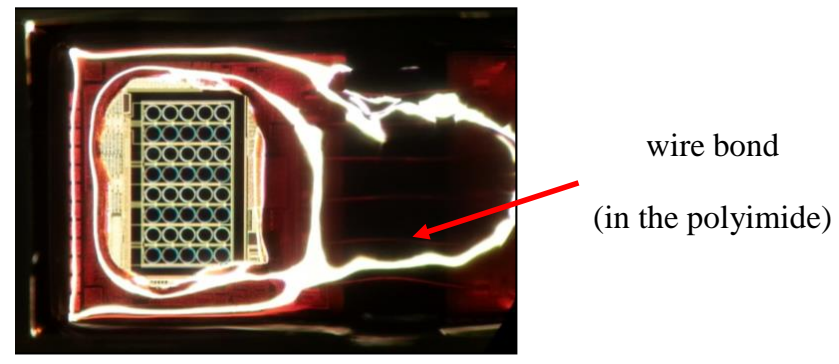

Figure 8. Casting of the entire sensor module before the ALD passivation. (b) Detailed image of the pressure sensor chip after the casting.

\subsection{Polyimide-epoxy composite deposition}

The potting of the chips and the bond wires with a polyimide-epoxy composite is cumbersome due to the lack of dimensional stability during the application process. The polyimide-epoxy composite flows over the chip surface depending on the material and topography making it difficult to control and predict area coverage. The pressure sensor membranes need to remain free of the polyimide-epoxy composite. Pre-heating of the chip carrier allows application of the polyimide-epoxy composite in certain areas only. The polyimide-epoxy composite was applied manually using a dispenser. For this reason the edge of the polyimide-epoxy composite around the area of the membranes is irregular.

A further critical point is the shrinkage of the material due to the evaporation of the solvent during curing. Preliminary tests showed that the $25 \mu \mathrm{m}$ AlSi bond wires were deformed by volume reduction of the polyimide-epoxy composite. In some samples, the deformation was so strong that the bond wires were pressed onto the chip edge resulting in electrical short circuits.

To avoid this problem, a high degree of imidization was achieved by heating the pressure sensor module up to $290^{\circ} \mathrm{C}$ for $1 \mathrm{~h}$. This temperature was selected to prepare the setup for the ALD deposition at a maximum temperature of $275^{\circ} \mathrm{C}$. In this way, no measurable shrinkage of the polyimide-epoxy was observed during the ALD deposition. The result of the polyimide-epoxy application after curing is shown in Fig. 8. 


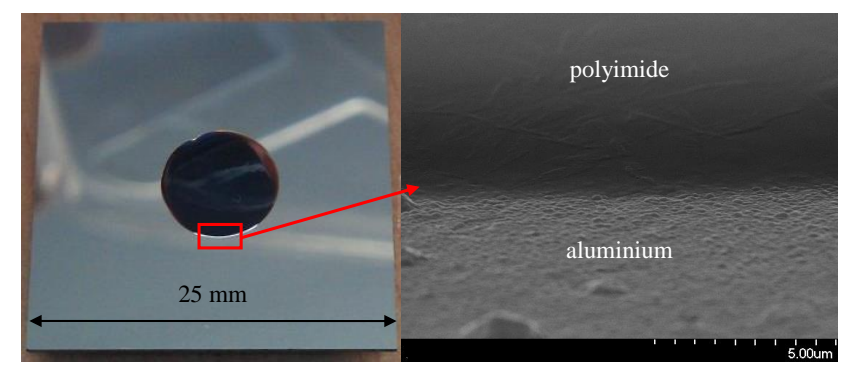

Figure 9. Photograph of a test chip (left) and SEM image of the transition region at a $45^{\circ}$ angle (right).

\section{ALD passivation}

\subsection{Material selection and layer thickness}

The requirements for the ALD passivation material are as follows:

- good adhesion to all materials (silicon, silicon nitride, polyimide-epoxy composite)

- must not alter the mechanical characteristic and properties of the pressure membranes

- conformal deposition of high surface topography

- biocompatible

- electrically insulating

- impermeable to water vapour

- corrosion resistant

- deposition at moderate temperatures to preserve the underlying potting material and CMOS circuitry.

Based on a previous study (Betz, 2011) aluminium oxide $\left(\mathrm{Al}_{2} \mathrm{O}_{3}\right)$ and tantalum pentoxide $\left(\mathrm{Ta}_{2} \mathrm{O}_{5}\right)$ were chosen as ALD layers. $\mathrm{Al}_{2} \mathrm{O}_{3}$ ensures good adhesion and conformity whereas the final $\mathrm{Ta}_{2} \mathrm{O}_{5}$ layer ensures excellent chemical resistance (Härkönen et al., 2011). It has also been demonstrated that $\mathrm{NaCl}$ solution has no measurable influence on $\mathrm{Ta}_{2} \mathrm{O}_{5}$ (Betz, 2011), ensuring biocompatibility.

It should be noted that the pressure sensor membrane deflection with $100 \mathrm{~nm} \mathrm{Ta}_{2} \mathrm{O}_{5}$ has been already examined by Betz (2011) with an optical interferometer. It was observed that the pressure-dependent deflection of a membrane was decreased by $19 \%$ compared to the unpassivated membrane. A reduction in pressure sensitivity of this magnitude can be easily compensated by the gain setting of the integrated readout circuit of the pressure sensor. Furthermore, the pressure sensor is designed so that the membrane touches the underlying substrate at a pressure of approximately $1.6 \mathrm{bar}$; therefore the maximum pressure survivability is rather high $(\sim 5$ bar $)$, definitely much higher than the maximum pressure experienced in an implant.

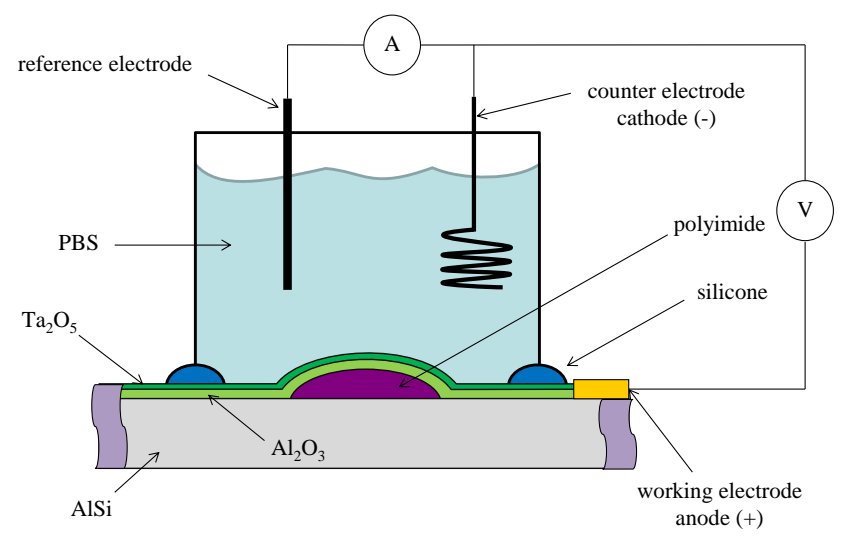

Figure 10. Schematic representation of the test setup for the amperometric defect investigation.

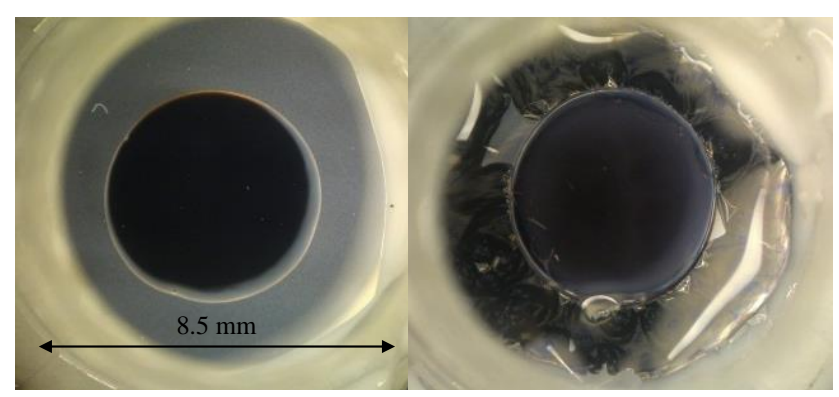

Figure 11. Intact probe after an amperometric defect test (left) and a sample having a defect in the ALD passivation (right). The sacrificial AlSi layer is completely decomposed.

Table 1 summarizes the process parameters for the deposition of the ALD layers.

\subsection{Investigation of the ALD passivation}

\subsubsection{Amperometric defect investigation of the ALD passivation layer on a test structure}

The interface between the chip surface and the polyimide is a critical area which had to be examined in more detail since fractures due to stress caused by the cooling process may damage the ALD passivation layers. Another failure mechanism is particle contamination. In order to locate defects in the passivation a destructive amperometric measurement test was carried out. For this purpose a silicon test wafer was fabricated with the following layers: $10 \mathrm{~nm} \mathrm{Ti}, 40 \mathrm{~nm}$ TiN, $900 \mathrm{~nm}$ AlSi deposited by sputtering.

The wafer was diced with a wafer-saw into individual chips with a size of $25 \times 25 \mathrm{~mm}^{2}$. Then, in a circular area of approximately $5 \mathrm{~mm}$ diameter polyimide-epoxy composite was applied manually with a dispenser and cured with the same parameters used for the pressure sensor module. This entire structure was coated with the ALD passivation layers. A first inspection by SEM, as shown in Fig. 9, revealed that 


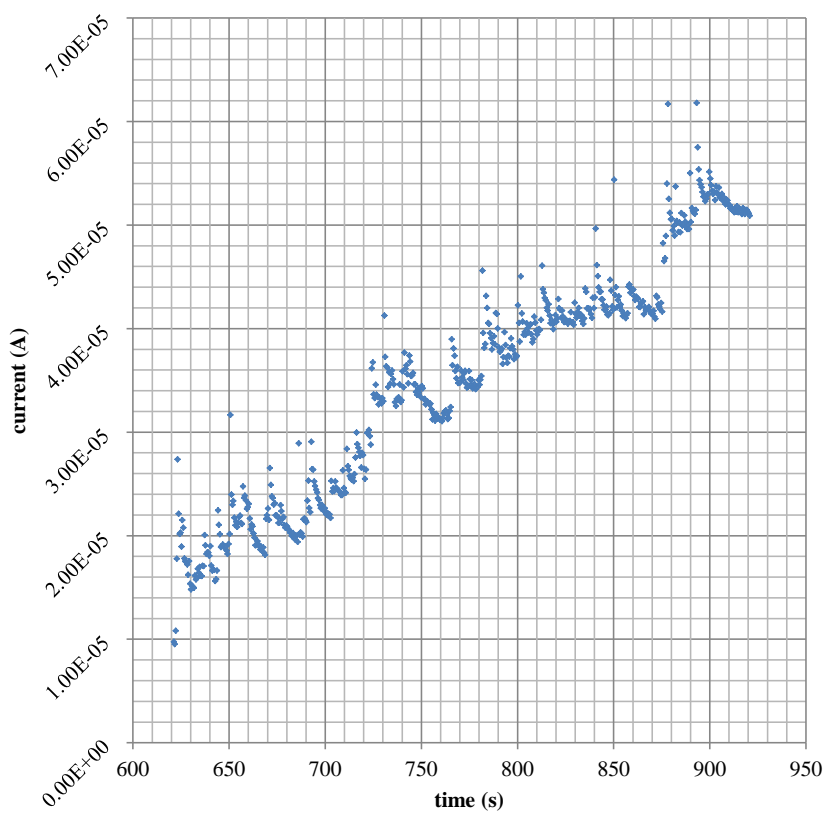

Figure 12. Current flow at a defective passivation at $3 \mathrm{~V}$.

in the transition region between the silicon sample and the polyimide no cracks were visible.

For the amperometric defect investigation, the test chips were prepared by gluing a plastic tube with silicone in the middle of the encapsulated region thus creating a container for PBS. The AlSi layer directly underneath the passivation test layers was used as the anode. The cathode and the reference electrodes were placed in the PBS. Figure 10 shows the measurement setup.

For the measurements an impedance analyser (Autolab $\mu A U T O L A B I I I / F R A 2)$ was used. An applied voltage between the electrodes resulted in no measurable current flow in the case of intact passivation. Contrarily, in the case of a defect in the ALD passivation layer, the AlSi layer began to decompose due to the contact with the electrolyte resulting in a measurable current flow of about $1 \mu \mathrm{A}$ which slowly increased. The AlSi layer directly below the passivation thus formed a sacrificial layer. To get an electrical contact to the AlSi layer the passivation was destroyed with a needle in the edge region. Figure 11 shows an optically intact sample (left) and a sample with a severe defect (right) after the amperometric test.

With the test samples the following amperometric measurements were carried out at room temperature: increasing the voltage from 1 to $5 \mathrm{~V}$ in $1 \mathrm{~V}$ steps for 5 minutes each and continuous measurement for $25 \mathrm{~h}$ at $5 \mathrm{~V}$. A voltage of $5 \mathrm{~V}$ was selected since many medical implants operate at this voltage.

The graph in Fig. 12 shows the current versus time for a sample with a defect. For the measurement using an increasing voltage the sample showed a first measurable current flow at a voltage of $3 \mathrm{~V}$ which continuously increased with time.

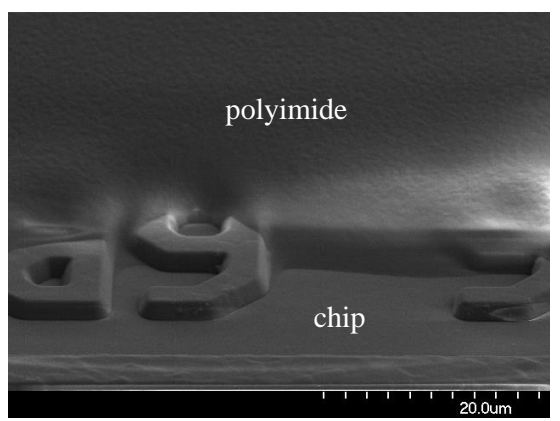

Figure 13. SEM image of boundary between polyimide-epoxy composite and chip surface with an ALD layer (not visible) over the entire area.

Table 1. Process parameters for the deposition of the passivation layers.

\begin{tabular}{|c|c|c|c|c|}
\hline Material & $\begin{array}{r}\text { Thickness } \\
{[\mathrm{nm}]}\end{array}$ & $\begin{array}{r}\text { Temperature } \\
{\left[{ }^{\circ} \mathrm{C}\right]}\end{array}$ & Cycles & $\begin{array}{r}\text { Growth rate per } \\
\text { cycles }[\AA]\end{array}$ \\
\hline $\mathrm{Al}_{2} \mathrm{O}_{3}$ & 50 & 270 & 500 & 1 \\
\hline $\mathrm{Ta}_{2} \mathrm{O}_{5}$ & 50 & 275 & 1300 & 0.4 \\
\hline
\end{tabular}

A sample without defect showed no measurable current flow, even after $25 \mathrm{~h}$ at $5 \mathrm{~V}$.

The preliminary tests showed that the adhesion of the polyimide-epoxy composites was sufficient despite the hightemperature stress it was exposed to. Dust particles were identified as the main source for defects; this is attributed to the fact that the test chips were not coated at wafer level. We tested four samples which were cleaned only with a stream of nitrogen before ALD. All of these samples showed defects. Four further samples were cleaned first with acetone, isopropanol and finally with DI-water; these showed no defects. The experiments indicated that the cleaning of the surface and full processing in clean-room conditions are important for a defect-free coating.

\subsubsection{Optical investigation of the sensor module}

The amperometric defect investigation showed that the transition region between silicon and polyimide-epoxy composite exhibited sufficient adhesion and that ALD passivation of polyimide-epoxy composite without fractures is in principle possible. Therefore, the pressure sensor modules were coated in the ALD tool. After the coating, a sample was analysed in the SEM. Figure 13 shows a close-up of the transition region between the chip surface and the polyimide-epoxy composite at an angle of $45^{\circ}$. It confirms that the transitional area could be coated despite the high topography of the ASICs without cracking or fractures.

Figure 14 shows the encapsulation of the entire pressure sensor chip as a SEM picture. The brightness is due to charg- 


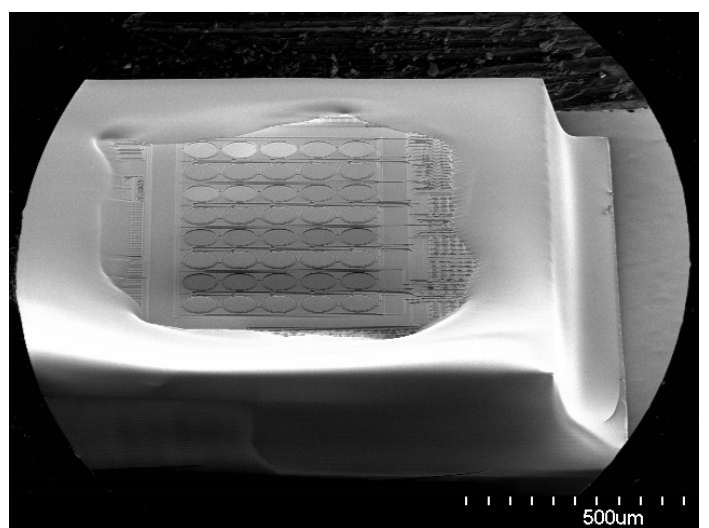

Figure 14. SEM image of a defect-free passivation.

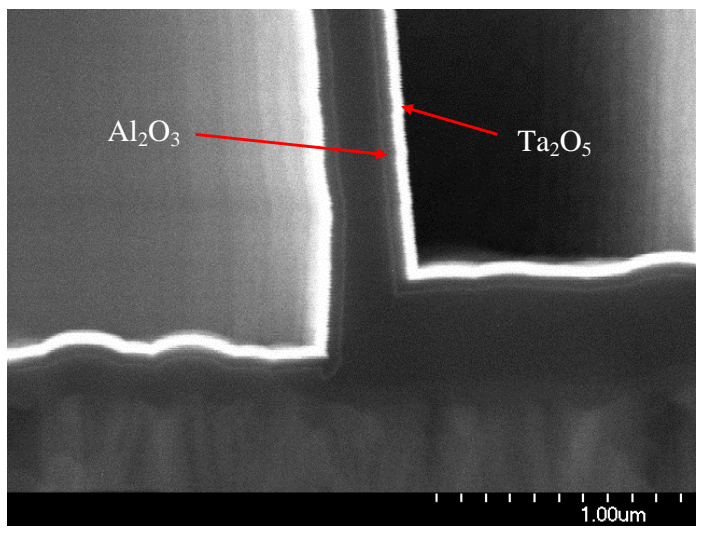

Figure 15. Cross-section SEM image of the ALD passivation layers.

ing of the tantalum pentoxide layer in the SEM, which has the benefit that defects can be detected easily.

Additionally, wafer pieces of pressure sensor chips were coated in the same ALD process step to control the layer thickness and conformity. Figure 15 shows an area of the pressure sensor after the ALD coating. The bright tantalum pentoxide layer on the surface is clearly visible and indicates excellent conformal coverage.

\section{Test and characterization of the sensor module after encapsulation}

Test measurements to evaluate and characterize the pressure sensor module after encapsulation were carried out. Prior to the measurement the sensor modules were calibrated allowing the temperature dependency of the pressure sensor to be compensated. The calibration took place in a pressure range from 800 to $1400 \mathrm{hPa}$ and a temperature range of 24 to $40^{\circ} \mathrm{C}$. The calibration parameters were controlled with a pressure calibrator DPI-520 and a PT-100 temperature sensor.

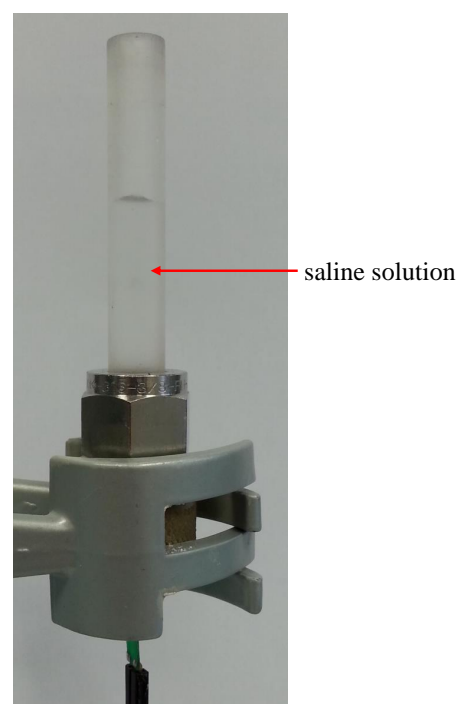

Figure 16. Photo of the housing with the transparent tube for holding the test fluid and creating a well-defined pressure.

\subsection{Housing for the sensor module}

To apply a defined pressure in a test fluid the pressure sensor module needed a suitable housing. The housing for the sensor module was made of polyether ether ketone (PEEK) which offers excellent chemical resistance and good temperature stability. The housing is designed in a modular way to facilitate different types of measurements. Figure 16 shows the calibration setup consisting of the PEEK housing and a transparent tube screwed onto the housing. Test liquid could then be dispensed into the tube creating a well-defined pressure.

The resulting liquid column provided a sufficient fluid reservoir. It also allowed connecting an air hose to apply a defined external pressure required for the calibration. The entire setup is placed in a climatic chamber to set the desired temperature.

\subsection{Measurement setup}

With the presented measuring system it is possible to measure not only pressure but also temperature. The measuring system consisted of the housed pressure sensor module placed in a climate chamber and connected with a hose to the pressure calibrator. The pressure sensor module transmits the measured values through a two-wire cable to a data reader device outside of the climatic chamber. The data reader contains the interface and energy controller (IEC) and a microcontroller. The IEC represents the link between the pressure sensor module and the microcontroller to control the communication and power supply. The data reader transmits the data via USB to a PC running a purpose programmed $L a b$ View software. The software visualizes and saves the measured values. The software also controls the pressure calibra- 


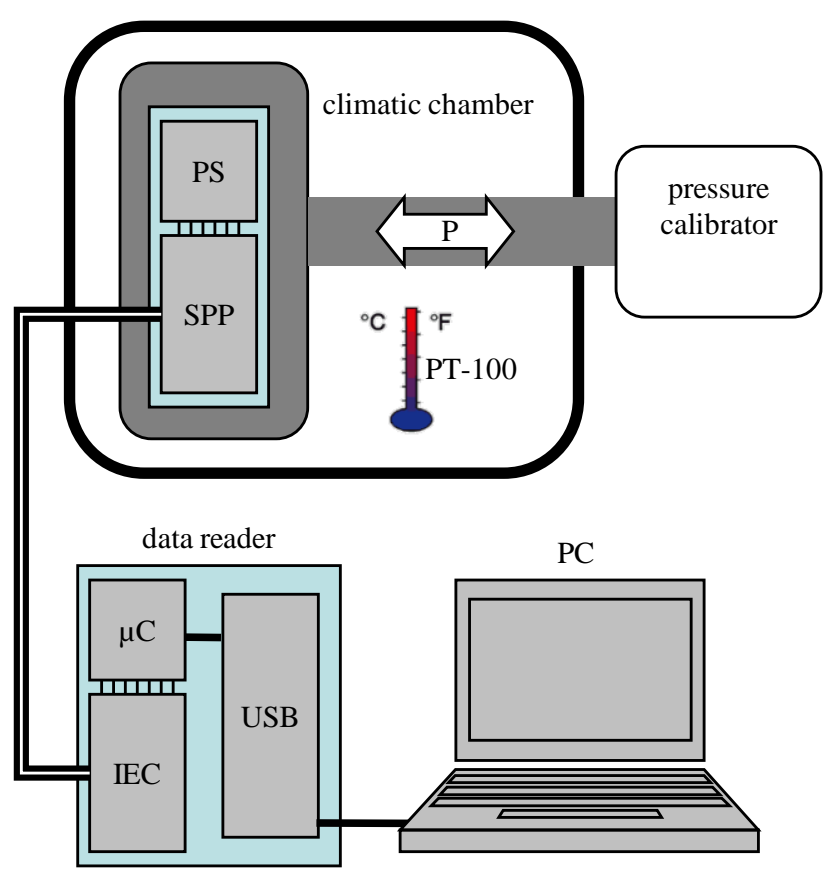

Figure 17. Overview of the pressure measurement system.

tor, measures the temperature in the climatic chamber with a PT-100 and programmes the climatic chamber to adjust the temperature. Figure 17 shows the main components of the measurement setup.

\subsection{Adjustment and calibration}

The digital output of the pressure sensor module is in a form of values between 0 and 8191 . The calibration of the pressure sensor module associates the digital values with the real pressure measured by a reference pressure sensor (DPI-520). To create a pressure calibration curve equidistant measurement points were selected. With two parameters it was possible to set the offset and the gain of the pressure sensor module and optimize the curve within certain limits. These parameters were introduced for compensating manufacturing tolerances and encapsulation influences.

The pressure curves used for calibration were recorded at various temperatures in $0.9 \%$ saline solution. Figure 18 shows an example of a calibration measurement against the reference pressure sensor. The pressure curves were recorded in a range of 800 to $1400 \mathrm{hPa}$ in a temperature range between 24 and $40^{\circ} \mathrm{C}$. In this resolution, the pressure curves almost overlap, indicating that the temperature coefficient of the pressure sensor module is very low.

With the measurement output values for the pressure $\left(z_{P}\right)$ and the temperature $\left(z_{T}\right)$ the real pressure is approximated

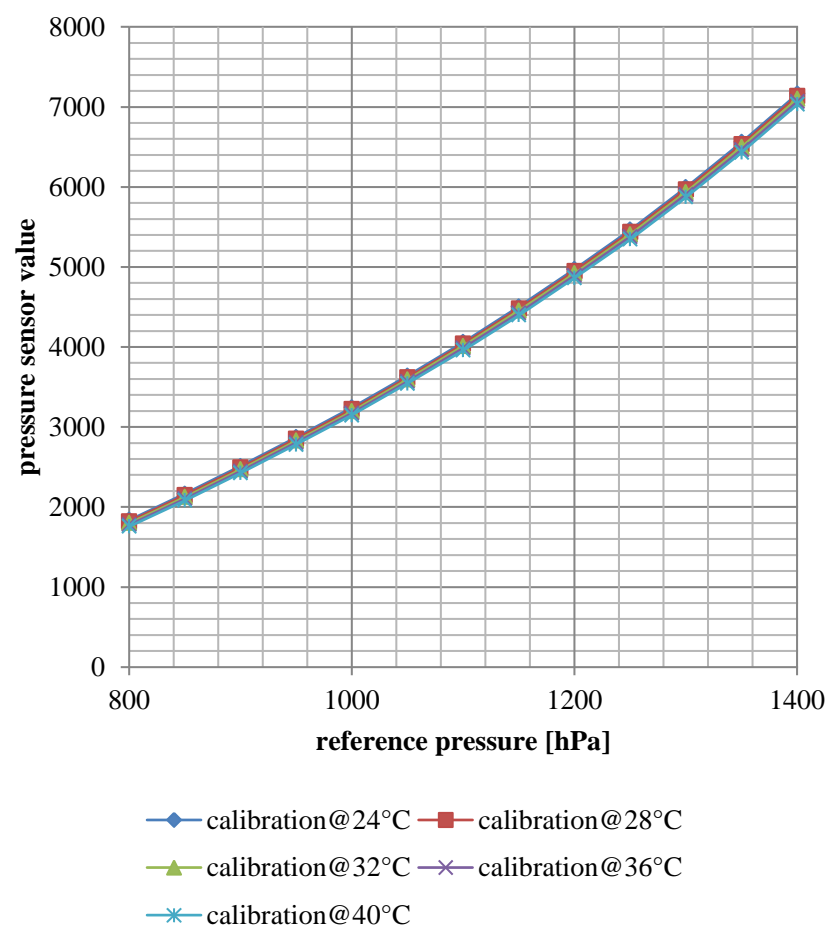

Figure 18. Pressure value of an encapsulated sensor module at various temperatures in saline solution.

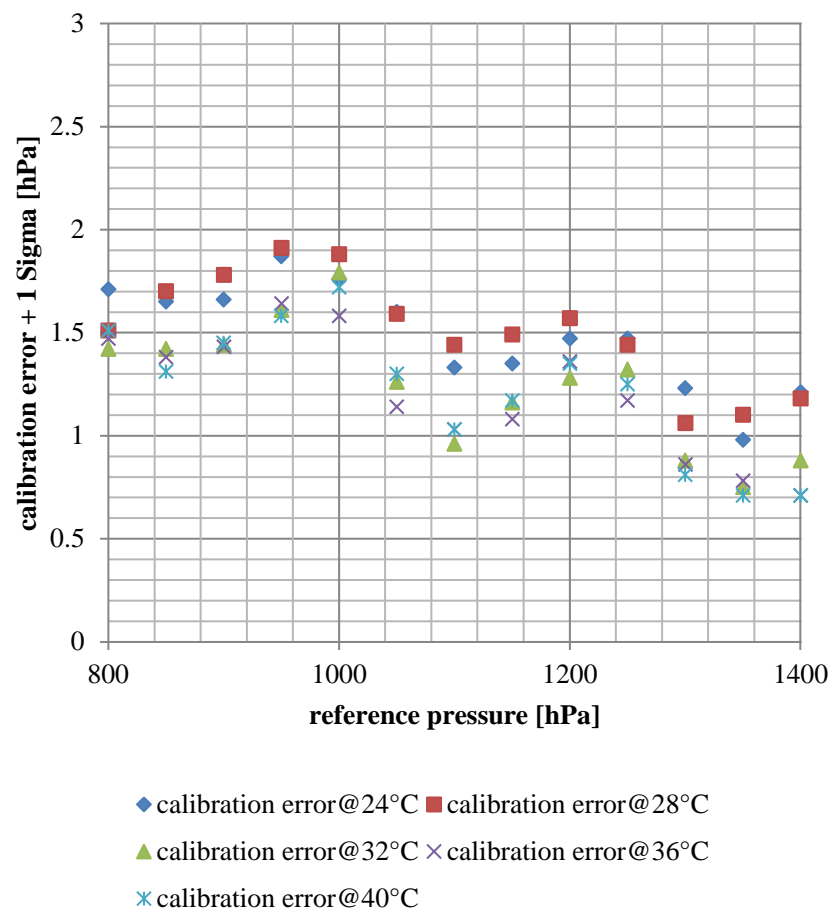

Figure 19. Pressure-calibration error (including 1-sigma noise) at different temperatures. 


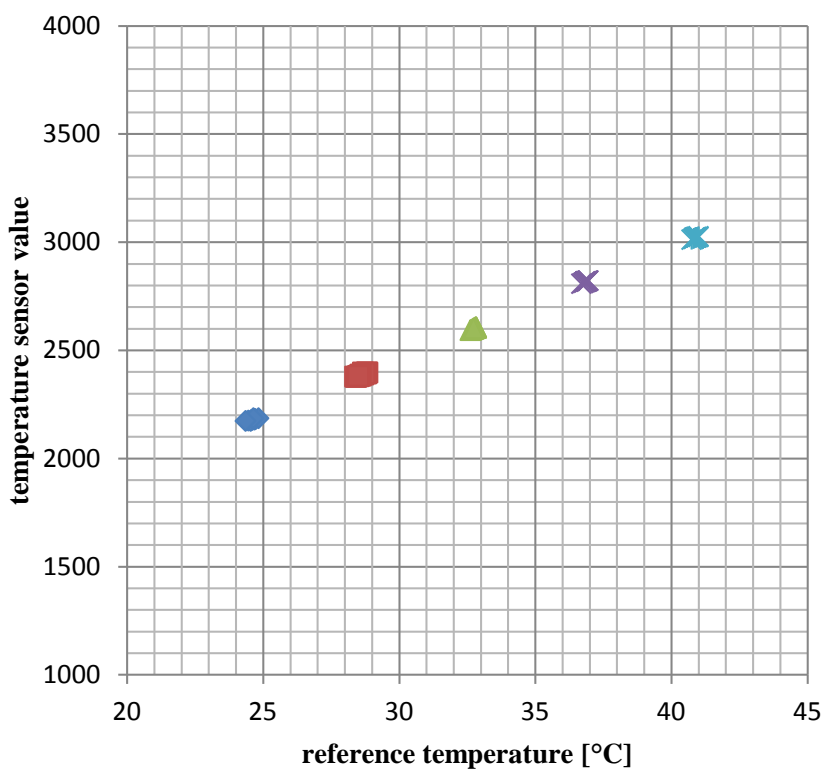

$\checkmark$ Kalibriermessung@ $24^{\circ} \mathrm{C}$

$\triangle$ Kalibriermessung@32 ${ }^{\circ} \mathrm{C}$

*Kalibriermessung@ $40^{\circ} \mathrm{C}$

Figure 20. Temperature value of an encapsulated sensor module at various temperatures in saline solution.

with a multivariable regression polynomial $P_{K}$ :

$P_{K}=\sum_{i=0}^{4}\left[\left(z_{P}\right)^{i} \sum_{j=0}^{2} a_{i, j}\left(z_{T}\right)^{j}\right]$.

The variable $\left(a_{i, j}\right)$ are the calibration coefficients of the polynomial witch are determined by the method of least squares.

For low temperature coefficients of the pressure sensor module (as for the measurement result shown in Fig. 18) calibration with the polynomial is possible. In Fig. 19 the calibration error of the pressure sensor module is shown, which is below $2 \mathrm{hPa}$ (including 1-sigma noise). Based on the measurement range this corresponds to a total error of about $0.34 \%$ full scale span.

Figure 20 shows the temperature sensor values at different pressures between 24 and $40^{\circ} \mathrm{C}$. The data points for the different pressures are very close together which demonstrates the good stability and reproducibility. As temperature reference a PT-100 was used. The calibration error of the temperature sensor shown in Fig. 21 is less than $0.2^{\circ} \mathrm{C}$ (including the 1-sigma noise)

\section{Accelerated life testing}

To estimate the long-term stability accelerated life tests of the pressure sensor modules were carried out. Several calibrated pressure sensor modules were placed in a sealed housing filled with $0.9 \%$ saline solution. The housed pressure

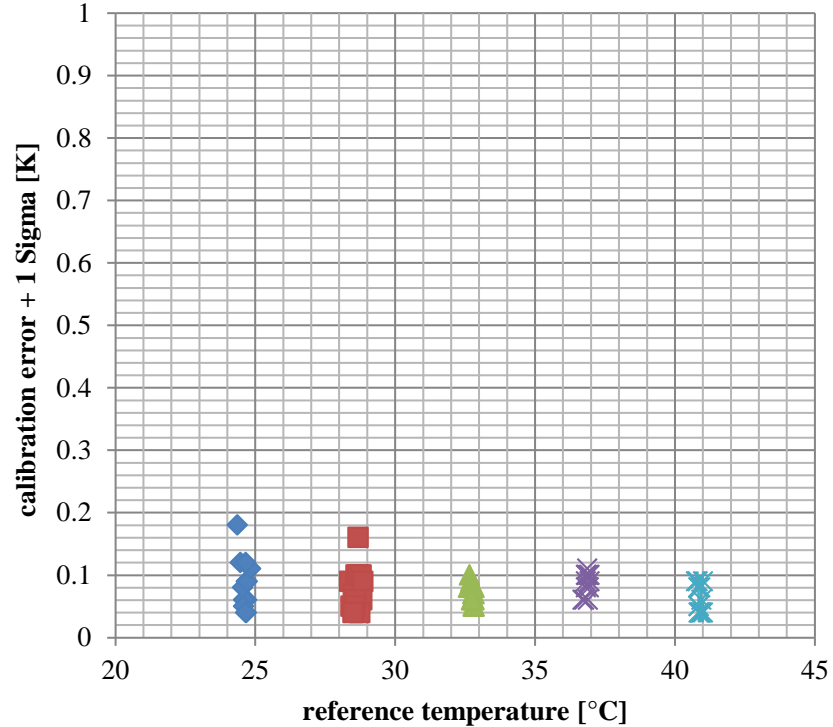

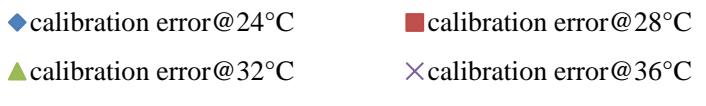

*calibration error@ $40^{\circ} \mathrm{C}$

Figure 21. Temperature-calibration error (including 1-sigma noise) at different temperatures.

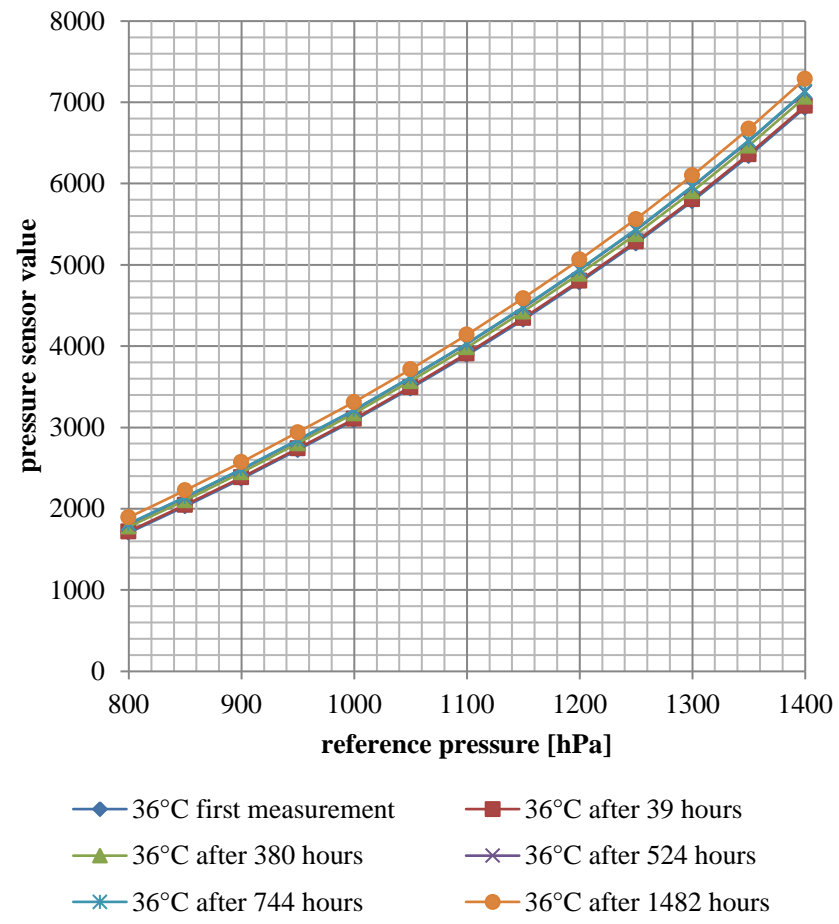

Figure 22. Pressure curves of different calibrations at $36^{\circ} \mathrm{C}$ after different periods of the accelerated life time test at $60^{\circ} \mathrm{C}$ in saline solution. 


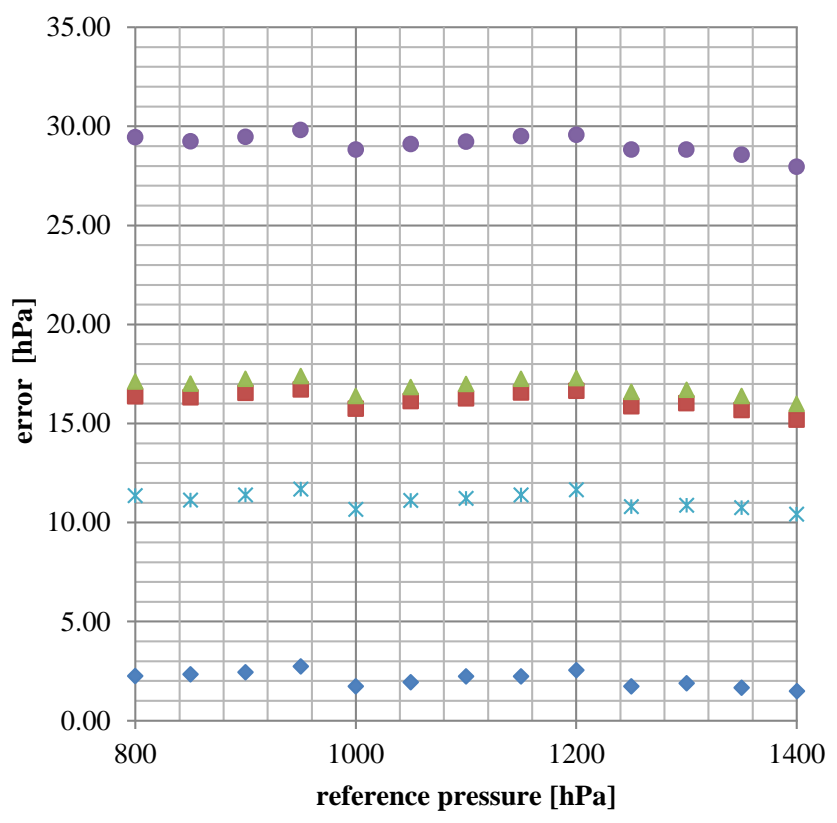

- after 39 hours $\quad *$ after 380 hours after 524 hours

$\triangle$ after 744 hours $\bullet$ after 1482 hours

Figure 23. Error of the pressure curves after a different accelerated life test time at $60^{\circ} \mathrm{C}$ in saline solution (the measurements were recorded at $36^{\circ} \mathrm{C}$ ).

sensor modules were stored in an oven at a temperature of $60^{\circ} \mathrm{C}$. This temperature was selected because the communication with the housed pressure sensor module was still functional at this temperature. The pressure sensor module was continuously electrically powered-up and read-out during the test. Higher temperatures would disturb the communication. To detect drift caused by environmental effects, the aging test was interrupted after certain time intervals and a control measurement was done to compare the results with the measurement before the start of the aging test. Control measurements were carried out at different temperatures and pressures. To illustrate the drift of the sensor module, pressure curves at $36^{\circ} \mathrm{C}$ of the control measurements at different time intervals of the aging test are shown in Fig. 22. After the control measurements, the sensor modules were placed back in the environmental chamber.

An upward shift of the pressure curves can be observed with increasing aging time. The calibration polynomial of the first measurement before the aging period was used to calculate the pressure value error. The measurement total calibration error in $\mathrm{hPa}$ is shown in Fig. 23. It should be noted that the housed pressure sensor module had to be removed from the oven and the housing opened before every control measurement to allow mounting the transparent tube for the pressure calibrator. This process is likely to cause mechanical stress on the housing and thus influence the sensor output. The error after $524 \mathrm{~h}$ and after $744 \mathrm{~h}$ of aging was about

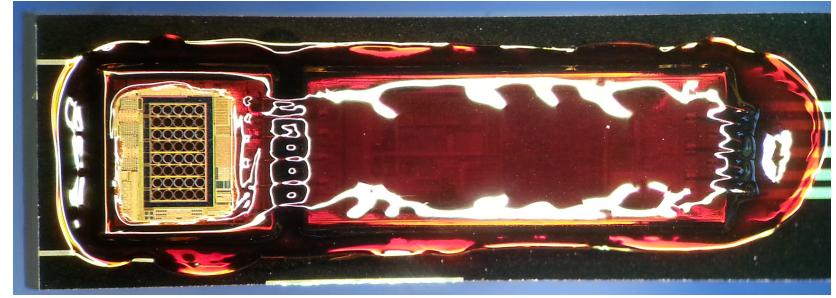

Figure 24. Photo of the sensor module with the wider silicon chip carrier.

$17 \mathrm{hPa}$. This corresponds to a total error of about $2.8 \%$ full scale. Between the measurement curves at 744 and $1482 \mathrm{~h}$ the complete pressure sensor module housing was opened for a visual investigation. The last measurement curve after $1482 \mathrm{~h}$ indicates that the system changed after the inspection as the error increased up to $30 \mathrm{hPa}$.

The sensor modules failed in continuous operation after a total of $1500 \mathrm{~h}$ at $60^{\circ} \mathrm{C}$ in saline solution. The reason for the failure is probably the saw line of the chip carrier which was not completely potted with the polyimide-epoxy composite in this design. Figure 24 shows a new design of a wider chip carrier, so that the polyimide does not extend to the saw lines of the chip carrier; this is likely to solve the problem.

The interpretation of the measurement data with respect to a prediction of long-term stability is not straightforward. Further accelerated aging tests at $100 \%$ humidity and a temperature of $120^{\circ} \mathrm{C}$ were carried out. The longest aging time here was $116 \mathrm{~h}$. We used an Arrhenius approach to calculate the operating life time at $37^{\circ} \mathrm{C}$ (Betz, 2011). We choose the activation-energy of $0.7 \mathrm{eV}$ to calculate operating life time as it is used for the aging of semiconductors in CMOS technology (White et al., 2013; Bayle and Mettas, 2010). Here, the influence of the liquid is not taken into account. The calculated life time at $37^{\circ} \mathrm{C}$ based on these tests was 3.3 years. An incorrect assumption on the value of the activation energy can lead to an incorrect deduction, which is the weakness of the acceleration model (Bayle and Mettas, 2010). If we use an activation-energy of $0.6 \mathrm{eV}$, the calculated life time at $37^{\circ} \mathrm{C}$ is 1.5 years and with an activation-energy of $0.8 \mathrm{eV}$ the calculated life time at $37^{\circ} \mathrm{C}$ is 7.5 years. For an unambiguous prediction of the life time a greater number of sensor modules have to be tested.

\section{Conclusion}

An encapsulation process has been developed to use a hightemperature resistant polyimide-epoxy composite as a dieattach material and sealing compound for the bond wire and parts of the chip surface excluding the MEMS pressure membranes. The process prepares the pressure-sensor module for ALD passivation. It could be shown that a conformal ALD of $\mathrm{Al}_{2} \mathrm{O}_{3}$ and $\mathrm{Ta}_{2} \mathrm{O}_{5}$ on a polyimide-epoxy composite is possible, including the transition regions to the chip surface. 
Moreover, it has been shown that a complete pressure sensor assembly can be encapsulated and hermetically sealed. The passivated pressure sensor was calibrated and tested in a $0.9 \%$ saline solution showing excellent results.

An accelerated life test at $60^{\circ} \mathrm{C}$ with permanent electric read-out indicated a maximum error of $5 \%$ full scale after $1482 \mathrm{~h}$. In a second accelerated life test at $120^{\circ} \mathrm{C}$ the passivated pressure sensor system reached an operation time of 116 hours until it fails. Using an Arrhenius approach with activation energy of $0.7 \mathrm{eV}$ the calculated life time at $37^{\circ} \mathrm{C}$ is 3.3 years. In order to get a better assessment of the life time, a greater number of sensor modules have to be tested.

Further optimization and automation of the fabrication process may allow a new kind of hermetic encapsulation for human implants based on MEMS sensors. As a next step, it is intended to test the pressure sensor module in blood and in an animal model in the near future. However, similar results are expected at least for the $\mathrm{Ta}_{2} \mathrm{O}_{5}$ layer, as has already been found to be more corrosion resistant in blood compared to bare Ti (Sun et al., 2013).

Edited by: R. Kirchner

Reviewed by: two anonymous referees

\section{References}

Bayle, F. and Mettas, A.: Temperature Acceleration Models in Reliability Predictions: Justification \& Improvements, Proceedings of Reliability and Maintainability Symposium (RAMS), Vol. 1, 25-28, 2010.

Betz, W.: Flexible mikroelektromechanische Implantate für den chronischen Einsatz: Verkapselungskonzepte und Testverfahren für die Materialcharakterisierung, $\mathrm{PhD}$-Thesis, Faculty of Engineering, University Duisburg-Essen, 2011.

Beyler, C. L. and Hirschler, M. M.: Thermal Decomposition of Polymers, Chapter in SFPE Handbook of Fire Protection Engineering, 3rd Edn., 2001.

Boyle, M. A., Martin, C. J., and Neuner, J. D.: Epoxy Resins, ASM Handbook, Composites, Vol. 21, 78-89, 2001.

Bradford, B., Krautschneider, W., and Schröder, D.: Wireless Power and Data Transmission for a Pressure Sensing Medical Implant, Proceedings of BMT 2010, Rostock-Warnemünde, Germany, 2010.

Calderón, J. B.: Oberflächenmodifizierung und -analytik von Polyimid, Dissertation, Faculty of Mathematics, Informatics and Natural Sciences, RWTH Aachen University, 2005.

Chen, P.-J., Rodger, D. C., Saati, S., Humayun, M. S., and Tai, Y.C.: Microfabricated Implantable Parylene-Based Wireless Passive Intraocular Pressure Sensors, J. Microelectromech. S., 17, 1342-1351, 2008.

Cheng, J., Li, J., and Zhang, J. Y.: Curing Behavior and Thermal Properties of Trifunctional Epoxy Resin Cured by 4, 4'Diaminodiphenyl Sulfone, Express Polym. Lett., 3, 501-509, 2009.

Cleven, N. J., Müntjes, J. A., Fassbender, H., Urban, U., Görtz, M., Vogt, H., Gräfe, M., Göttsche, T., Penzkofer, T., Schmitz-Rode, T., and Mokwa, W.: A Novel Fully Implantable Wireless Sensor
System for Monitoring Hypertension Patients, IEEE T. Bio-Med. Eng., 59, 3124-3130, 2012.

Dudaicevs, H., Kandler, M., Manoli, Y., Mokwa, W., and Spiegel, E.: Surface Micromachined Pressure Sensors with Integrated CMOS Read-Out Electronics, Sensor Actuat. A-Phys., 43, 157163, 1994.

Eick, S., Wallys, J., Hofmann, B., van Ooyen, A., Schnakenberg, U., Ingebrandt, S., and Offenhäusser, A.: Iridium Oxide Microelectrode Arrays for in Vitro Stimulation of Individual Rat Neurons from Dissociated Cultures, Frontiers in Neuroengineering, Vol. 2, doi:10.3389/neuro.16.016.2009, 2009.

Gaw, K. O. and Kakimoto, M.: Polyimide-Epoxy Composites, Progress in Polyimide Chemistry I, Advances in Polymer Science, 140, 107-136, 1999.

Gembaczka, P., Görtz, M., Kordas, N., Lerch, R., Müntjes, J., Kraft, M., and Mokwa, W.: Integrated Capacitive Pressure Sensor for an Implantable Wireless System for Measuring Pressure in the Pulmonary Artery, Proceedings of Mikrosystemtechnik 2013 Von Bauelementen zu Systemen, Aachen, Germany, 2013.

Gräfe, M., Göttsche, T., Osypka, P., Görtz, M., Trieu, H. K., Fassbender, H., Mokwa, W., Urban, U., Schmitz-Rode, T., Hilbel, T., Becker, R., Bender, B., Coenen, W., Fähnle, M., and Glocker, R.: HYPER-IMS: A Fully Implantable Blood Pressure Sensor for Hypertensive Patients, Proceedings of Sensor + Test Conference, 2009.

Ha, D., de Vries, W. N., John, S. W. M., Irazoqui, P. P., and Chappell, W. J.: Polymer-Based Miniature Flexible Capacitive Pressure Sensor for Intraocular Pressure (IOP) Monitoring Inside a Mouse Eye, Biomedical Microdevices, 14, 207-215, 2012.

Hang Tng, D. J., Hu, R., Song, P., Roy, I., and Yong, K.-T.: Approaches and Challenges of Engineering Implantable Microelectromechanical Systems (MEMS) Drug Delivery Systems for in Vitro and in Vivo Applications, Micromachines, 3, 615-631, 2012.

Härkönen, E., Díaz, B., Światowska, J., Maurice, V., Seyeux, A., Vehkamäki, M., Sajavaara, T., Fenker, M., Marcus, P., and Ritala, M.: Corrosion Protection of Steel with Oxide Nanolaminates Grown by Atomic Layer Deposition, J. Electrochem. Soc., 158, 369-378, 2011.

Hassler, C., Boretius, T., and Stieglitz, T.: Polymers for Neural Implants, J. Polym. Sci. Pol. Phys., 49, 18-33, 2011.

Loeb, G. E.: Cochlear Prosthetics, Annu. Rev. Neurosci., 13, 357371, 1990.

Mokwa, W.: Medical implants based on microsystems, Measurement, Sci. Technol., 18, R47, doi:10.1088/0957-0233/18/5/R01, 2007.

Müntjes, J., Meine, S., Flach, E., Görtz, M., Hartmann, R., SchmitzRode, T., Trieu, H. K., and Mokwa, W.: Assembly of a Pulmonary Artery Pressure Sensor System, Acta Polytechnica, 50, 56-59, 2010.

Park, J. and Lakes, R. S.: Biomaterials: An Introduction, 3rd Edn., Springer, 2007.

Polytec PT GmbH: Duralco 4461, Data Sheet, 2010.

Polytec PT GmbH: Polytec EP P-690, Data Sheet, 2011.

Rezai, A. R., Finelli, D., Nyenhuis, J. A., Hrdlicka, G., Tkach, J., Sharan, A., Rugieri, P., Stypulkowski, P. H., and Shellock, F. G.: Neurostimulation Systems for Deep Brain Stimulation: In Vitro Evaluation of Magnetic Resonance Imaging-Related Heating at 1.5 Tesla, JMRI-J. Magn. Reson. Im., 15, 241-250, 2002. 
Rubehn, B. and Stieglitz, T.: In Vitro Evaluation of the Long-Term Stability of Polyimide as a Material for Neural Implants, Biomaterials, 31, 3449-3458, 2010.

Schlierf, R., Görtz, M., Schmitz-Rode, T., Mokwa, W., Schnakenberg, U., and Trieu, H. K.: Pressure Sensor Capsule to Control the Treatment of Abdominal Aorta Aneurisms, Proceedings of the 13th International Conference on Solid-State Sensors, Actuators and Microsystems, 2, 1656-1659, Seoul, South Korea, 2005.

Stangel, K., Kolnsberg, S., Hammerschmidt, D., Hosticka, B. J., Trieu, H. K., and Mokwa, W.: A Programmable Intraocular CMOS Pressure Sensor System Implant, IEEE J. Solid-St. Circ., 36, 1094-1100, 2001.

Sun, Y.-S., Chang, J.-H., and Huang, H.-H.: Corrosion Resistance and Biocompatibility of Titanium Surface Coated with Amorphous Tantalum Pentoxide, Thin Solid Films, 528, 130-135, 2013.
Trieu, H. K.: Surface Micromachined Pressure Sensors for Medical Applications, Proceedings of Sensor + Test Conferences, Nuremberg, Germany, 2011.

Walewyns, T., Reckinger, N., Ryelandt, S., Pardoen, T., Raskin, J. P., and Francis, L. A.: Polyimide as a Versatile Enabling Material for Microsystems Fabrication: Surface Micromachining and Electrodeposited Nanowires Integration, J. Micromech. Microeng., 23, 095021, doi:10.1088/0960-1317/23/9/095021, 2013.

White, M., Cooper, M., Yuan Chen, and Bernstein, J.: Impact of Junction Temperature on Microelectronic Device Reliability and Considerations for Space Applications, Proceedings of Integrated Reliability Workshop Final Report, IEEE International, 133-136, 2003. 